\title{
Applied behaviour analysis and standard treatment in intellectual disability: 2-year outcomes ${ }^{\dagger}$
}

\author{
Angela Hassiotis, Anton Canagasabey, Daniel Robotham, Louise Marston, Renee Romeo \\ and Michael King
}

\begin{abstract}
Summary
Applied behaviour analysis by a specialist team plus standard treatment for adults with intellectual disability displaying challenging behaviour was reported to be clinically and costeffective after 6 months. In a 2-year follow-up of the same trial cohort, participants receiving the specialist intervention had significantly lower total and subdomain Aberrant
\end{abstract}

Behavior Checklist scores than those receiving usual care alone. After adjustment for baseline covariates there was no significant difference in costs between the trial arms.

\section{Declaration of interest}

None.
The development of multidisciplinary teams to provide specialised care for problem behaviours in people with intellectual disabilities is one of the key recommendations of the revised Mansell report in the UK. ${ }^{1}$ Such teams may effectively support adults with a variety of problem behaviours that are not adequately managed by existing standard services. In the USA, behaviour support services have been set up as a result of lawsuits that obliged various states to fund such teams in order to apply behaviour analytic treatments to people with both mental disorders and intellectual disabilities. ${ }^{2}$ However, research into the effectiveness of such treatment has been scarce. In an earlier trial, we reported that applied behaviour analysis in addition to standard treatment significantly reduced problem behaviours, measured by the Aberrant Behavior Checklist $(\mathrm{ABC}){ }^{3}$ and decreased costs compared with standard treatment alone after 6 months. ${ }^{4}$ We reassessed participants 2 years after randomisation to investigate whether the significant reduction in challenging behaviours and apparent cost savings were sustained beyond the original trial duration of 6 months. To our knowledge, this is the longest follow-up for any intervention in intellectual disability.

\section{Method}

The method and results 6 months after randomisation have been reported elsewhere. ${ }^{4}$ In brief, 63 participants with problem behaviours were recruited from community intellectual disabilities services in one area of England between 2005 and 2007 Participants were randomly allocated to the specialist behaviour service in addition to standard treatment $(n=32)$ or to standard treatment alone $(n=31)$. All staff in the specialist behaviour service had obtained similar training in order to deliver treatment based on applied behaviour analysis. Standard treatment included multidisciplinary interventions by medical, nursing and other professionals. Approval from the local research ethics committee was obtained for collection of individual and case-note data. No attempt was made to keep participants in their randomised groups beyond the planned 6-month end-point of the trial. D.R. contacted all participants in the trial and administered the same assessment instruments as at the 6-month follow-up. Data were gathered on the main outcome of problem behaviours, measured

†See editorial, pp. 428-430, this issue. with the $\mathrm{ABC}$, and on the secondary outcomes of mental status and service use, measured using the Psychopathology Assessment Schedules for Adults with Developmental Disabilities (PAS-ADD) checklist and the Client Service Receipt Inventory (CSRI) respectively. ${ }^{5,6}$ Adverse events such as death and loss to follow-up were also recorded.

\section{Cost analysis}

The costs associated with both arms of the trial were estimated from a health and personal social services system perspective. These included any non-psychiatric out-patient consultations with professionals where the reason for the visit could not be directly attributed to mental disorder (e.g. for various physical ailments). In the case of non-psychiatric in-patient services, these refer to medical treatment (e.g. for dehydration). Unit costs of in-patient admissions were taken from the specialty and programme cost returns to the UK Department of Health. ${ }^{7}$ Other unit costs were based on nationally applicable figures. ${ }^{8}$ Costs were compared between the intervention and standard treatment groups for the 6 months prior to the 2-year follow-up point and based on 58 cases for which data were available.

\section{Statistical analysis}

The analyses presented here are based on intention to treat. A two-level linear model for the total $\mathrm{ABC}$ score and a three-level multivariate outcome model for its constituent subscales were used, all transformed by taking their square root. Analyses of the dichotomous outcome PAS-ADD domains were modelled using generalised estimating equations. All models were adjusted for baseline scores of the main outcome as well as time period as a categorical variable. Multivariate regression analysis was used to adjust total costs at follow-up for baseline covariates (total costs at baseline, age, gender, PAS-ADD mental state diagnoses, autismspectrum disorder based on clinical records and the $\mathrm{ABC}$ total score). Analyses were carried out using Stata version 10.1 and MLwiN version 2.15 (www.cmm.bristol.ac.uk/MLwiN) on Windows.

\section{Results}

By the 6-month follow-up point, one participant in each arm had died and a third had withdrawn from the intervention arm. At 2 


\begin{tabular}{|c|c|c|c|c|}
\hline Domain & $\begin{array}{l}\text { Difference in mean transformed scores between } \\
\text { standard treatment and intervention } \\
\text { Mean (s.e.) }\end{array}$ & $\begin{array}{l}\text { Square root } \\
\text { of baseline subscale score } \\
\text { Coefficient (s.e.) }\end{array}$ & $\begin{array}{l}\text { Between-patient } \\
\text { variance } \\
\text { Mean (s.e.) }\end{array}$ & $\begin{array}{l}\text { Between-time- } \\
\text { period variance } \\
\text { Mean (s.e.) }\end{array}$ \\
\hline Total irritability & $-0.44(0.22)$ & $0.59(0.07)$ & $0.51(0.16)$ & $0.97(0.13)$ \\
\hline Lethargy & $-0.44(0.22)$ & $0.58(0.06)$ & $0.69(0.20)$ & $1.08(0.14)$ \\
\hline Stereotypy & $0.02(0.18)$ & $0.47(0.05)$ & $0.25(0.09)$ & $0.70(0.09)$ \\
\hline Hyperactivity & $-0.66(0.24)$ & $0.59(0.05)$ & $0.48(0.16)$ & $1.08(0.14)$ \\
\hline Inappropriate speech & $-0.21(0.14)$ & $0.67(0.04)$ & $0.10(0.06)$ & $0.52(0.07)$ \\
\hline
\end{tabular}

years, another two participants had dropped out. Therefore, data were available for 29 intervention and 29 standard treatment alone participants post trial (mean follow-up contact 15.6 months, s.d. =7.12). Eight participants in the standard treatment only group changed over to the specialist behaviour team plus standard treatment during that period.

The mean duration of engagement with the specialist behaviour team in the intervention arm was 16 months (s.d.=6.4). At 2 years, participants in the intervention arm had significantly lower transformed total $\mathrm{ABC}$ scores than those in standard treatment (mean $-0.88,95 \%$ CI -1.66 to -0.11 ). The differences in the $\mathrm{ABC}$ subdomains irritability, hyperactivity and lethargy remained significantly lower in favour of the intervention (Table 1). Further details of the ABC scores are shown in online Table DS1. At 2 years there remained an excess of organic conditions in the standard treatment arm ( $\mathrm{OR}=0.03,95 \% \mathrm{CI} 0.00$ to 0.60$)$. Similar proportions of service users in each group made contact with community services (online Table DS2). However, in the standard treatment group, three service users received intensive community support (average 4.5 times per week for approximately $45 \mathrm{~min}$ each time). This is reflected in the high average cost of community-based services for the standard treatment arm, which offset the costs of the intervention arm.

After adjustment for baseline covariates the care package costs of standard treatment were no different from the cost of the specialist intervention plus standard treatment (mean difference UK£810, 95\% CI -3986 to 5629) (online Table DS3).

\section{Discussion}

Our main finding was that the specialist behaviour team intervention plus standard treatment arm continued to show significant clinical gains beyond the initial 6 months of the trial. We were able to follow up $92 \%$ of the original participants. We are aware of the limitation that randomisation could not be retained after 6 months. Although residual confounding is a possibility in trial follow-up studies, this limitation is to some extent offset by the high rate of follow-up achieved. The increase in organic disorders in the standard treatment arm is likely to be either an artefact or the result of enduring problem behaviours. We were unable to establish any new diagnosis of cognitive impairment during the follow-up period.

The additional cost of the specialist behaviour team did not add significantly to treatment costs at follow-up. Communitybased care was the only cost component significantly higher in the standard treatment arm, contributing as much as $91 \%$ of the care input. After adjustment for baseline covariates, intervention plus standard treatment was cost-neutral. This result is important, given that antipsychotic medication is not costeffective in the treatment of aggressive behaviours in people with intellectual disabilities when quality of life and service implications are considered. ${ }^{9}$ The relatively small numbers in our trial and the variance of the cost data mean, however, that confirmation in larger studies of service provision is required. Initial proof that systematic assessment and management of problem behaviours by trained professionals may improve clinical outcomes in the longer term for individuals with severe and complex needs at no extra cost is particularly important in the context of recent UK government policy, which favours the wide implementation of this service model. ${ }^{10}$

Angela Hassiotis, MA, PhD, FRCPsych, Research Department of Mental Health Sciences, University College London; Anton Canagasabey, FRCPsych, South Essex Partnership NHS University Foundation Trust, Billericay; Daniel Robotham, MSC, PhD, Mental Health Foundation, Billericay, London; Louise Marston, MSc, Department of Primary Care and Population Health, University College London; Renee Romeo, PhD, Health Services and Population Research Department, Centre for the Economics of Mental Health, Institute of Psychiatry, London; Michael King PhD, FRCPsych, Research Department of Mental Health Sciences, University College London Medical School, UK

Correspondence: Angela Hassiotis, Research Department of Mental Health Sciences, Charles Bell House, 67-73 Riding House Street, London W1W 7EY, UK. Email: a.hassiotis@ucl.ac.uk

First received 15 Dec 2009, final revision 22 Jun 2010, accepted 22 Jul 2010

\section{References}

1 Department of Health. Services for People with Learning Disabilities and Challenging Behaviour or Mental Health Needs (Revised Edition). Department of Health, 2007 (http://www.dh.gov.uk/prod_consum_dh/ groups/dh_digitalassets/@dh/@en/documents/digitalasset/dh_080128.pdf).

2 Rohr ME. Consultation regarding behavior services improvement. In Contemporary Dual Diagnosis: MH/MR Service Models, vol 2, Partial and Supportive Services (eds JW Jacobson, S Holburn, JA Mulick): 67-75. NADD Press, 2002.

3 Aman MG, Singh NN, Stewart AW, Field CJ. The Aberrant Behavior Checklist: a behavior rating scale for the assessment of treatment effects. Am J Ment Defic 1985; 89: 485-91.

4 Hassiotis A, Robotham D, Canagasabey C, Romeo R, Langridge D, Blizard R, et al. Randomized, single-blind, controlled trial of a specialist behavior therapy team for challenging behavior in adults with intellectual disabilities. Am J Psychiatry 2009; 166: 1278-85.

5 Prosser H, Moss S, Costello H. The Psychiatric Assessment Schedule for Adults With a Developmental Disability (PAS-ADD) Checklist. University of Manchester, Hester Adrian Research Centre, 1998.

6 Beecham J. Collecting and estimating cost. In The Economic Evaluation of Mental Health Care (ed M Knapp): 61-82. Ashgate, 1995.

7 Department of Health. National Health Services Schedule of Reference Costs, 2006. Department of Health, 2006 (http://dh.gov.uk/nhsexec/refcosts.htm).

8 Curtis L (ed). Unit Cost of Health and Social Care, 2007. University of Kent Personal Social Services Research Unit, 2007.

9 Romeo R, Knapp M, Tyrer P, Crawford M, Oliver-Africano P. The treatment of challenging behaviour in intellectual disabilities: cost-effectiveness analysis. J Intell Disability Res 2009; 53: 633-43.

10 Mansell J. Raising Our Sights: Services for Adults with Profound Intellectual and Multiple Disabilities. Department of Health, 2010 (http://www.dh.gov.uk/prod_consum_dh/groups/dh_digitalassets/@dh/@en/ documents/digitalasset/dh_117961.pdf). 